\title{
Biological and Ethological Response of Black Sea Golden Grey Mullet (Chelon auratus Risso, 1810) Fries to Different Salinities and Temperatures
}

\author{
Victor Nita ${ }^{1, *}$ (D), Magda Nenciu ${ }^{1}$
}

${ }^{1}$ NIMRD - National Institute for Marine Research and Development “Grigore Antipa”, 300 Mamaia Blvd., RO-900581, Constanta, Romania.

\section{Article History}

Received 09 March 2020

Accepted 10 September 2020

First Online 14 September 2020

\section{Corresponding Author}

Tel.: +40722454962

E-mail:vnita@alpha.rmri.ro

\section{Keywords}

Chelon auratus

Salinity

Temperature

Aquaculture

\begin{abstract}
The aim of this paper was to investigate the biological and ethological response of golden grey mullet Chelon auratus (Risso, 1810) fries collected from Romanian Black Sea shallow waters to different salinities and temperatures, in order to document the optimal conditions for controlled rearing. The species' potential for aquaculture is enhanced by its eurihalyne and eurithermal adaptability, allowing it to grow in a variety of ecosystems, including the Romanian Black Sea area, with its highly variable salinity and temperature specificities. Three experimental set-ups were designed: a salinity tolerance test, with 5 salinity regimes $(0.3 \%$ o, $5 \%, 10 \%, 15 \%$ ond $20 \%$ o, a temperature tolerance experiment, involving both temperature decrease (down to $8^{\circ} \mathrm{C}$ ) and increase (up to $34^{\circ} \mathrm{C}$ ), and an extreme salinity test, reaching a maximum value of $95 \%$. The aggregated results obtained from the three experiments indicated that golden grey mullet fries can indeed tolerate a wide range of temperatures $\left(8^{\circ} \mathrm{C}-36^{\circ} \mathrm{C}\right)$ and salinities ( $5 \%$ - $70 \%$ ), with the optimal range between $10 \%$ ond $30 \%$ salinity, at temperatures of $10^{\circ} \mathrm{C}-25^{\circ} \mathrm{C}$. The practical purpose of this investigation was supporting the diversification of local mariculture species, as mullets can be excellent candidates for the enhancement of aquaculture in the area
\end{abstract}

\section{Introduction}

Along with other members of the Mugilidae family, the golden grey mullet Chelon auratus (Risso, 1810) inhabits coastal lagoons and estuaries, where they constitute target species for artisanal fisheries (Katselis et al., 2007). They also play a crucial ecological role as biotic vectors of organic matter between littoral habitats and the open sea (Lefeuvre et al., 1999). For a long time, mullets have been considered among the most interesting coastal species for aquaculture (Pillia, 1975; Mansour, 2013). Approximately 20 mullet species have been cultured in many regions of the world (Lee, 1997).

Golden grey mullet is spread in the Mediterranean, Black and Caspian Seas, as well as along the Atlantic coast, and culture in extensive and semi-intensive enclosures has been practiced worldwide for centuries, especially in the Far East and the Mediterranean (Crosetti \& Cataudella, 1995), reaching a global production of 134,329 tons in 2010 (Mylonas et al.,, 2019). The species' potential for aquaculture is enhanced by its eurihalyne and eurithermal adaptability, allowing it to grow in a variety of ecosystems (Crosetti \& Cataudella, 1995). Moreover, fry production is high in certain seasons, and their capture almost entirely supports seed supply for mullet aquaculture (Crosetti \& Cataudella, 1995). Golden grey mullets are consumers of the low trophic layers and can therefore be used in most economic and efficient way by culturing them extensively (Crosetti \& Cataudella, 1995). They also possess osmoregulation abilities which appear early during the development (Nordlie et al., 1982) and allow them to maintain elevated growth rates also under hyposaline conditions (Cardona \& CastelloOrvary, 1997). For this reason, mullets are widely 
cultivated in freshwater and brackish ponds (Allen, 1991; Olukolajo \& Omolara, 2013).

Because of being euryhaline and eurytherm, mullets can tolerate salinity degrees between $0 \%$ and $60-70 \%$ and survive at water temperature between $0^{\circ} \mathrm{C}$ and $38^{\circ} \mathrm{C}$ and they can also survive for a long time at dissolved oxygen levels as low as 0.32 ppm (Cardona, 2000; Bozkurt \& Secer, 2001). Thus, their production may be carried out in a variety of eco-systems like coastal lagoons with brackish to hyper saline waters (Hotos \& Vlahos, 1998), reservoirs and ponds with fresh waters (Losse et al., 1991) or even as supplementary crops in carp ponds (Crosetti \& Cataudella, 1995). Moreover, grey mullet aquaculture has the advantage of providing not only affordable whole fish and fillets, but also fish roe, a high value product ( $>100 € / \mathrm{kg}$ ), whose market is expanding around the Mediterranean, for instance. C. auratus can reach 4-6 $€ / \mathrm{kg}$ on the Greek market (Hotos \& Katselis, 2011). Therefore, mullets have a great biological and economical potential for fish species and product diversification, and development of value-added products.

A market for grey mullet is well established, though a niche one, in the Mediterranean. Even without any marketing effort by the aquaculture industry, the European market demand for grey mullet is likely to increase in the coming years, due to the demand from established and newly immigrant families originating from North Africa, Middle East and Asia. Currently, the industry is a capture-based aquaculture, relying exclusively on capture of wild fry (ca 1,000,000,000) that are subsequently grown out to market weight (600$1,200 \mathrm{~g}$ ) in captivity, in lagoons or earthen ponds (Mylonas et al., 2019).

In this context, in addition to performing research experiments on rearing highly valuable finfish species, such as sturgeons (Russian sturgeon Acipenser gueldenstaedti and Siberian sturgeon Acipenser baerii), turbot (Scophthalmus maximus) (Niță \& Nenciu, 2017), the golden-grey mullet's potential for culture was tested in a Recirculating Aquaculture System within NIMRD (Niță et al., 2018).

The aim of this complex research was to investigate the biological and ethological response of golden grey mullet fries collected from Romanian Black Sea shallow waters to different salinities and temperatures, in order to document the optimal conditions for controlled rearing. The practical purpose of this investigation was supporting the diversification of local mariculture species.

\section{Materials and Methods}

\section{Fish Collection and Acclimation}

The collecting procedure of $C$. auratus fries was conducted in a way to minimize habitat disturbance and unnecessary mortality of fish. Transport plastic tanks were disinfected before use (EPA, 2002; American
Fisheries Society, 2004). Thereby, the C. auratus fries used for this experiment were collected using appropriate mesh size hand nets from the Mamaia Bay area, located close to NIMRD's premises, placed in a 40 liter plastic barrel and transported to the laboratory. The fish were gently transferred from the barrels to the acclimation tank, making sure that temperature difference between the barrels and the tank was not higher than $3^{\circ} \mathrm{C}$. The fish were acclimated in a $900 \mathrm{I}$ fibre glass tank in a flow-through system (UV sterilized water) at a flow of approximately $100 \mathrm{l} /$ hour and properly aerated, in order to obtain around 80 - 90\% dissolved oxygen (DO) saturation. The fish were maintained for 14 days in the acclimation tank (EPA, 2016) and fed with JBL Novo Grano Mix mini pellets, at an approximate ration of $2 \%$ of total fish biomass in the tank (Zaharia et al., 2017). Subsequently, the same feeding ration was given to all fish involved in the three experiments. During the acclimation period, fish health was monitored daily, in order to observe any signs of illness that may cause a change in the fish' natural behaviour.

\section{Salinity Tolerance Experiment}

The $C$. auratus fries, previously acclimated for 14 days, were divided into 5 experimental batches. 5 glass aquaria provided with air flow, with a total volume of 7 I of water/aquarium, were used. The 5 tanks were filled with water at different salinity levels, as follows: $0.3 \%$ (dechlorinated tap water), 5\%, 10\%, 15\%o and 20\%. For higher salinities, standard Instant Ocean sea salt was added, in order to obtain the required salt concentration. After the experimental aquaria were prepared, fish were extracted from the acclimation tank and distributed using a randomization procedure. Because it is generally extremely difficult for experimenters to eliminate bias using only their expert judgment, the use of randomization in experiments is common practice (Suresh, 2011). The fish were carefully extracted from the acclimation tank individually using a fish net. Following a randomization block scheme (https://www.randomlists.com), the fish were placed one by one in 5 plastic buckets filled with seawater. When reaching the desired number (10) of individuals per bucket, the contents of each bucket was strained through a net and subsequently fish were placed in the matching labelled experimental aquarium (Figure 1).

The salinity tolerance experiment covered a period of 56 days ( 8 weeks) and the parameters monitored in each experimental aquarium were: temperature $\left({ }^{\circ} \mathrm{C}\right)$, salinity (\%o), $\mathrm{pH}$ and dissolved oxygen (DO) (\%), twice a week, using a Mettler Toledo SevenExcellence Multiparameter. Moreover, initial standard fish length $(\mathrm{mm})$ and weight $(\mathrm{mg})$ were measured. In order to determine the growth performance in the different salinity regimes, a final measurement (after 8 weeks) was performed. The maximum standard length (SL) of the specimens was measured on a measuring board to the nearest 1 millimetre. The total weight $(\mathrm{W})$ of the fish 


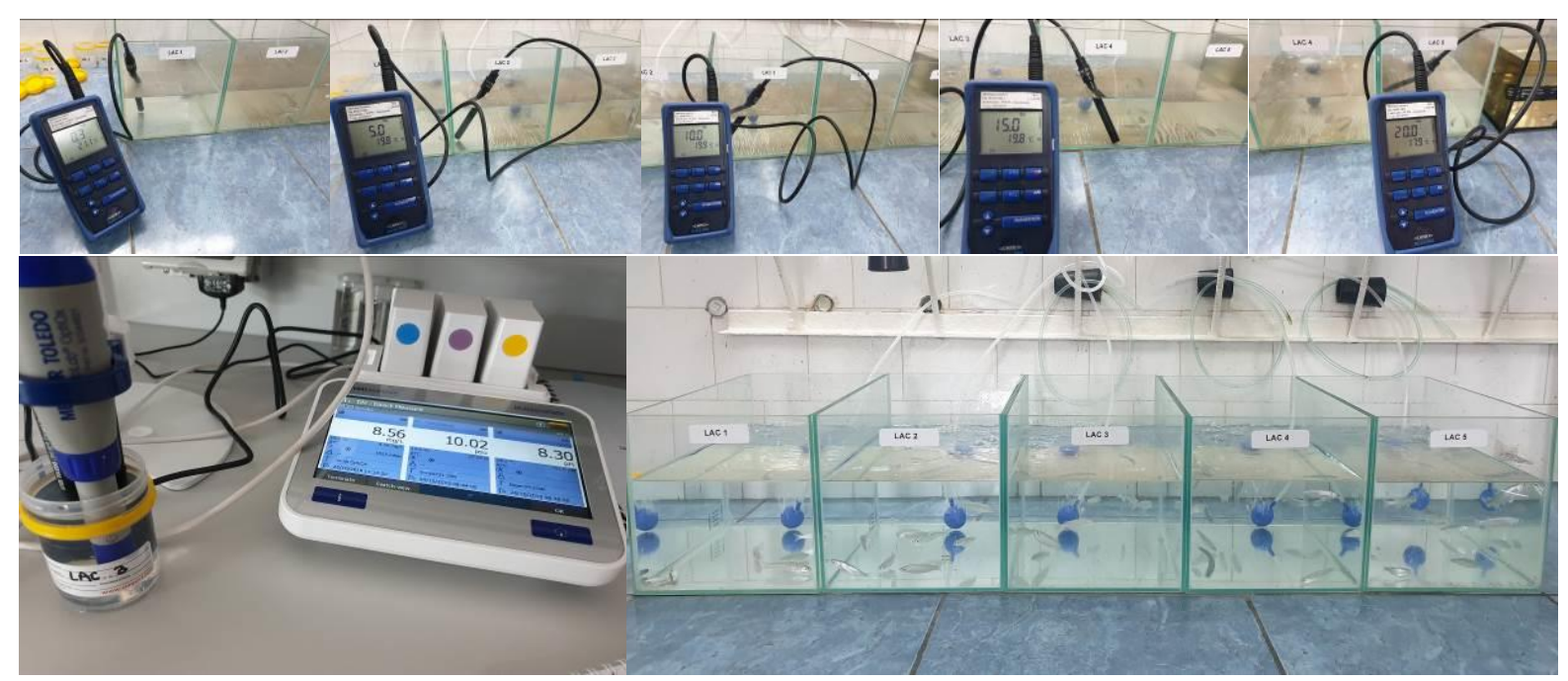

Figure 1. Salinity tolerance experimental set-up: individual tanks salinity measurements (up); pH and DO (\%) measurements (down left); overview of test aquaria (down right) (original photos).

was taken on a Kern EW top loading balance.

Fulton's Condition Factor $(\mathrm{K})$ was calculated using the equation: $\mathrm{K}=\left(\mathrm{W} / \mathrm{L}^{3}\right) * 100$, where $\mathrm{W}$ is the total weight $(\mathrm{mg}), \mathrm{L}$ is the maximum standard length $(\mathrm{mm})$ (Reis \& Ateş, 2019).

Mortalities were recorded daily in each experimental aquarium.

\section{Temperature Tolerance Experiment}

Two batches of $C$. auratus fries (30 individuals each), previously acclimated for 14 days in the fiber glass acclimation tank, were introduced in two glass aquaria, carefully avoiding extracting fish having signs of distress/abnormal behavior (Barton \& Iwama, 1991).

The temperature tolerance experiment was designed in two directions: increasing temperature in one aquarium and decreasing water temperature in the other, starting from a $20^{\circ} \mathrm{C}$ baseline. For water cooling, the test aquarium was placed in a temperaturecontrolled room, while for water heating a professional JBL Pro Temp S300 heater was used. Both experimental batches were progressively adapted by modifying the controlled room/water heater temperature with $1-1.5^{\circ} \mathrm{C}$ each day, starting from an initial temperature of $20^{\circ} \mathrm{C}$. Thus, after 10 days of experiment, fish were brought to $8^{\circ} \mathrm{C}$ in the temperature-controlled room, while in the heated aquarium the maximum water temperature was $34^{\circ} \mathrm{C}$. Proper aeration was provided in both experimental aquaria - an air flow of about 50l/hour, in order to obtain around $80-90 \%$ DO saturation (depending on conditions - temperature, number of fish, etc.) and water recirculation/filtration/protein skimming.

The observations performed during the temperature tolerance experiments focused on general fish behavior and adaptation to cold/warm water (swimming, feeding etc.). Mortalities were recorded daily in each experimental aquarium.

\section{Extreme Salinity Tolerance Test}

After completion of the salinity and temperature tests, an extreme conditions experiment was performed. Using the same aquarium for the temperature tolerance test, standard Instant Ocean sea salt was added, progressively increasing salinity over a period of 36 days, starting from $20 \%$ and reaching a maximum value of $95 \%$. A professional JBL Pro Temp S300 heater was used, water temperature being kept very high, with peak of $36^{\circ} \mathrm{C}$.

\section{Euthanasia and Disposal}

At the conclusion of the salinity and temperature tolerance tests, the surviving fish from each aquarium were strained through a net and placed in a glass jar (1 I) filled with iced water. When observing complete immobility, the fish were individually extracted, and the spinal cord was rapidly sectioned using a sharp scalpel. The euthanized fish were then placed in labelled zip-lock bag and stored in a freezer until collection for disposal by a specialized company (AVMA, 2013).

\section{Results and Discussion}

\section{Salinity Tolerance Experiment}

The salinity tolerance experiment was designed to cover a rather long period of 56 days ( 8 weeks), in order to allow quantifying the changes in fish length and weight. The results of measurements performed are summarized in Table 1 below.

It was noticed that increases in fish length were recorded in all salinity regimes, with the highest in the $15 \%$ and $0.3 \%$ aquaria (by $8.82 \%$ and $8.24 \%$, respectively), the latter results being statistically influenced by the small number of fish for the final measurement ( 3 surviving fish out of 10 ). The lowest fish 
length increase was recorded, however, in the $20 \%$ regime, as fish grew only by $4.10 \%$ (Figure 2). Overall, except for the $20 \%$ salinity, all fish grew more in length than in weight, regardless of the salinity regime (Figure 2).

As far as the evolution of fish weight is concerned, it was notable that the highest increase (by $12.04 \%$ ) was recorded in the $20 \%$ salinity regime, while in the freshwater aquarium the weight increase was negative $(-2.05)$, yet this results were statistically influenced by the small number of fish for the final measurement $(3$ surviving fish out of 10) (Table 1, Figure 2). For the remaining salinities, weight gains were positive, slightly increasing in correlation with salinity (by $0.43 \%, 3.04 \%$ and $3.22 \%$, corresponding to $5 \%, 10 \%$ ond $15 \%$ o salinities, respectively) (Table 1, Figure 2).

Fulton's Condition Factor $(\mathrm{K})$ is another measure of an individual fish's health that uses standard weight. Thus, in order to better assess the state of $C$. auratus at the different salinities tested, it was calculated both after the initial and final measurements. The values were calculated using the length and weight from the final measurements and show a correlation between the Condition Factor and salinity. The results obtained indicate an overall good state of the fries, with $\mathrm{K}$ values ranging between 1.35 and 1.72 , with the best condition being reported for fish kept at a $20 \%$ o salinity (Figure 3 ). Our results are consistent with other findings for mullet species (Verdiell-Cubedo, 2006; Guino-o, 2012).

During the entire experimental period, water parameters in the 5 test aquaria were monitored. Temperature was kept constant, ranging between $19.5^{\circ} \mathrm{C}$ and $19.7^{\circ} \mathrm{C}$, in order not in influence in any way the state and behavior of fish. $\mathrm{pH}$ values were normal in all experimental aquaria (8.22-8.55), while dissolved oxygen (DO) percentages increased with salinity (from $94.4 \%$ at $0.3 \%$ o to 102.5 at $20 \%$ o).

The survival percentage of fish in all salinity regimes was $100 \%$, except for the $0.3 \%$ aquarium, where mortalities occurred in the first week (first and second day) of the test ( 2 and 5 dead fish, respectively)

Regarding the ethology of $C$. auratus during the experimental period, the swimming and feeding behavior were carefully observed. After the initial stress of being handled for length and weight measurements, the fish placed in the test aquaria started swimming and feeding normally, with slight differences between the different salinities. Thus, the fish kept at $0.3 \%$ salinity

Table 1. Summary of $C$. auratus length and weight in the different salinity regimes.

\begin{tabular}{|c|c|c|c|c|c|c|c|c|c|c|}
\hline Measurements & Length & Weight & Length & Weight & Length & Weight & Length & Weight & Length & Weight \\
\hline Salinity & \multicolumn{2}{|c|}{$0.3 \%$} & \multicolumn{2}{|c|}{$5 \%$} & \multicolumn{2}{|c|}{$10 \%$} & \multicolumn{2}{|c|}{$15 \%$} & \multicolumn{2}{|c|}{$20 \%$} \\
\hline $\begin{array}{l}\text { Initial 21.10.2019 } \\
\text { Final }\end{array}$ & 43.7 & 1460 & 42.5 & 1392 & 43.4 & 1514 & 43.1 & 1582 & 44.4 & 1520 \\
\hline 16.12.2019 & 47.3 & 1430 & 44.7 & 1398 & 45.9 & 1560 & 46.9 & 1633 & 46.2 & 1703 \\
\hline Increase by \% & 8.24 & -2.05 & 5.18 & 0.43 & 5.76 & 3.04 & 8.82 & 3.22 & 4.10 & 12.04 \\
\hline
\end{tabular}

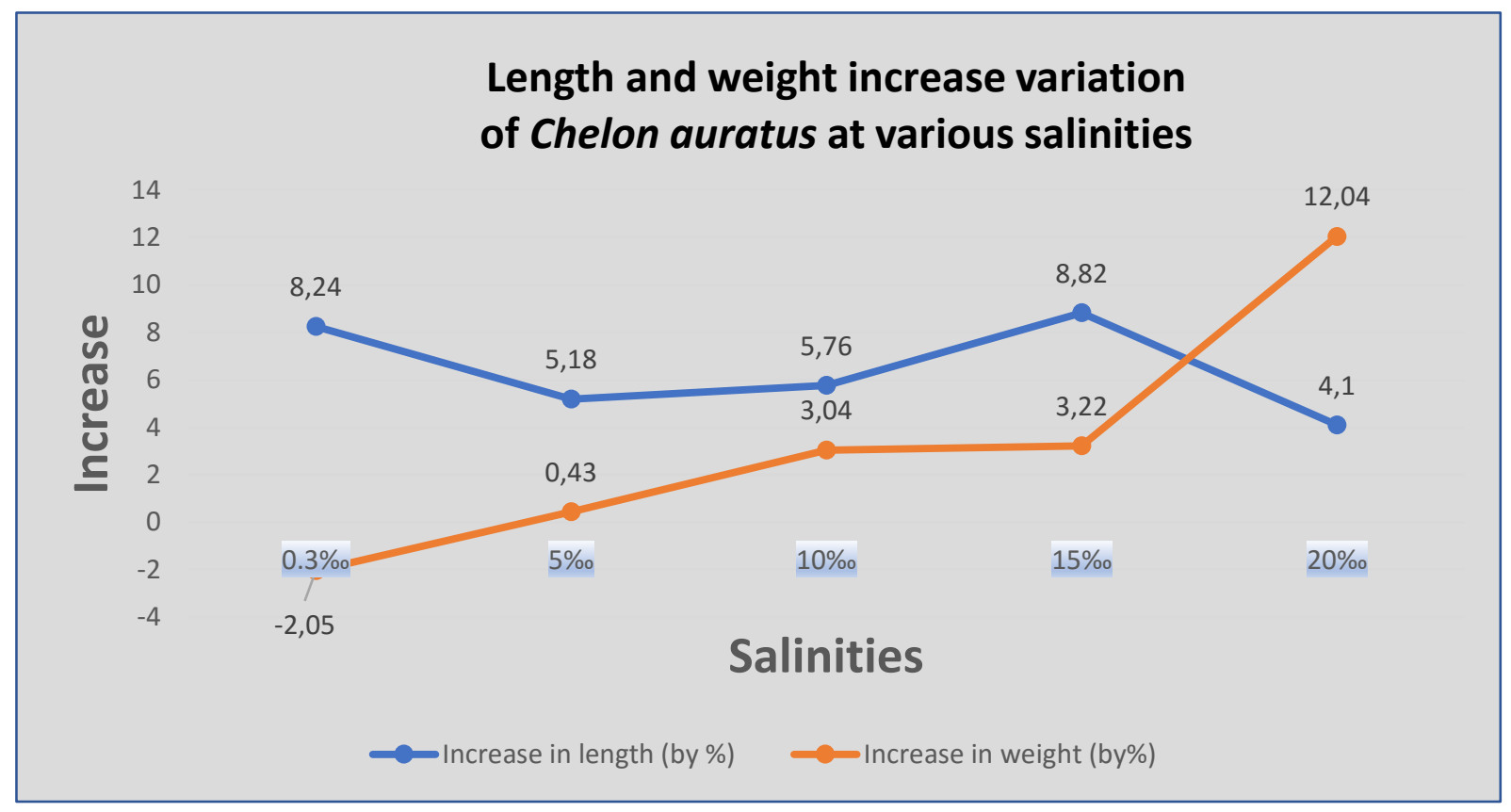

Figure 2. Comparative length and weight increase variation of $C$. auratus at various salinities. 


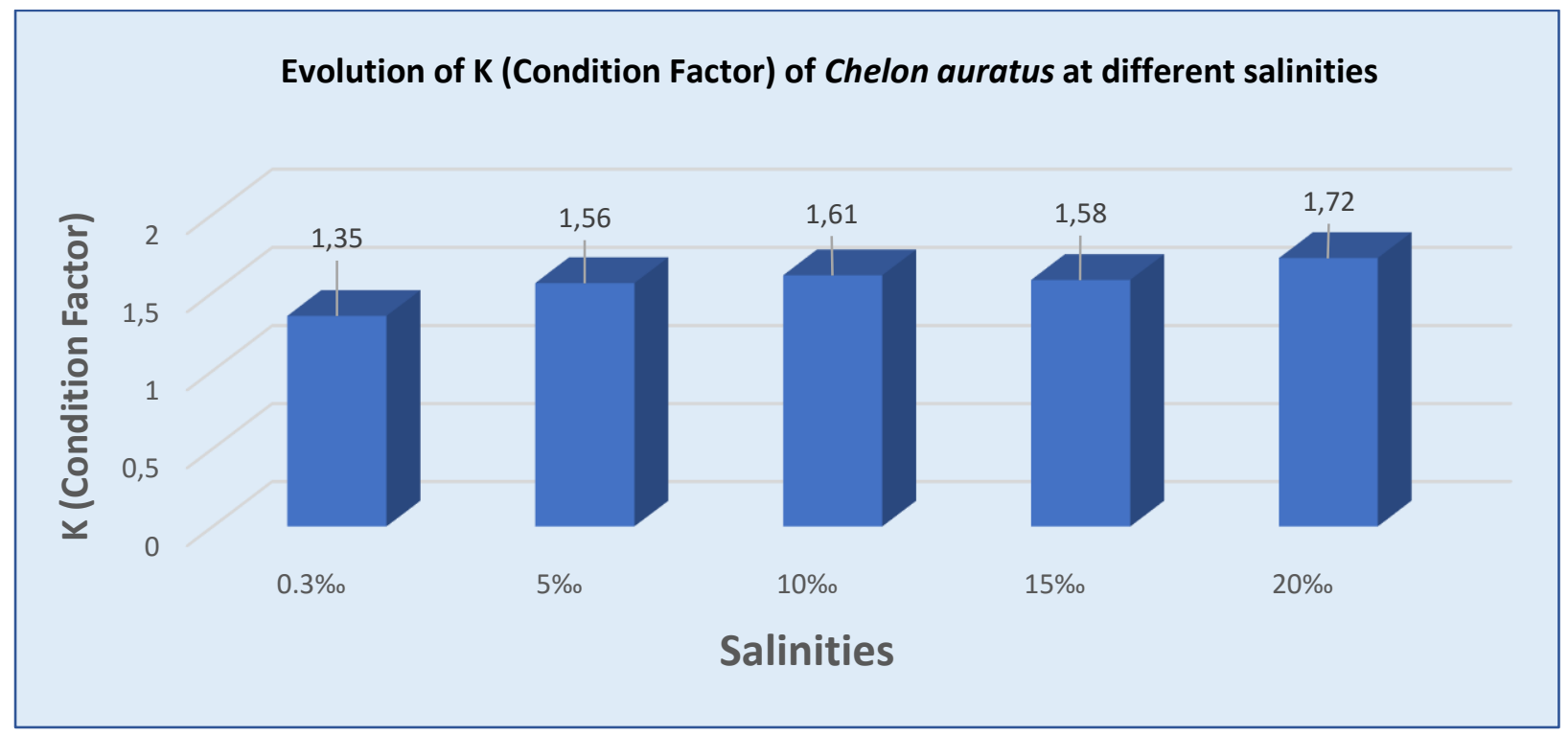

Figure 3. Evolution of $\mathrm{K}$ (Condition Factor) of $C$. auratus at various salinities.

were less mobile and less voracious while feeding and significant amounts of pellets were left uneaten on the bottom. In the 5\%o aquarium, swimming was more active, however some of the food was still left not consumed. In the higher salinity tanks, namely at $10 \%$, $15 \%$ and $20 \%$ o concentrations, all fish were swimming actively and full consumption of the pellets was observed throughout the experimental period.

These findings are consistent with the evolution of length, weight and condition factor of the tested fish, and indicate that the optimal salinity range for golden grey mullet fries is between $10 \%$ and $20 \%$ o salinity, which make them very appropriate for Black Sea rearing conditions (with salinities ranging between $13.03 \%$ 20.98\%o) (Nicolaev et al., 2019). Moreover, C. auratus fries can tolerate even lower salinities (5\%o), with no major disturbances of growth and overall behaviour, which makes them good candidates for brackish Black Sea water aquaculture.

\section{Temperature Tolerance Experiment}

During the temperature tolerance test, salinity was maintained constant around $16 \%$, yet a slight increase was observed in the warm water aquarium, due to evaporation caused by higher temperatures (around 19\%o maximum).

In the cold-water set-up, no mortalities were recorded during the experimental period. The general behaviour was good and fish were observed feeding and swimming normally down to a $10-11^{\circ} \mathrm{C}$ water temperature. Below this threshold and down to the final temperature of $8^{\circ} \mathrm{C}$, swimming became less active and food consumption reduced, but fish still continued to feed.

Regarding the warm water experiment, progressive temperature increase resulted in an accelerated swimming speed, fish becoming more and more active along with the temperature rise. Beyond $25^{\circ} \mathrm{C}$, the feeding behaviour started to be affected, the fish eating less, yet continuing to feed up to the final temperature of $34^{\circ} \mathrm{C}$. No mortalities were recorded in the warm water experimental aquarium.

The temperature tolerance test revealed that golden grey mullet fries can tolerate a wide range of temperature (from $8^{\circ} \mathrm{C}$ to $34^{\circ} \mathrm{C}$ ), with an optimal range for rearing between $10-25^{\circ} \mathrm{C}$. These findings, correlated with the usual Romanian Black Sea water temperatures ranging between $4.4^{\circ} \mathrm{C}$ and $24^{\circ} \mathrm{C}$ (Nicolaev et al., 2019), indicate $C$. auratus as a species with good potential for diversifying local aquaculture.

\section{Extreme Salinity Tolerance Test}

After completion of the temperature tolerance test, the 30 fish in the warm water aquarium were maintained and a progressive increase of temperature and salinity was applied. The maximum temperature induced using the JBL Pro Temp S300 heater was $36^{\circ} \mathrm{C}$. Salinity was increased daily (from $20.5 \%$ ), reaching an extreme value of $95 \%$. Dissolved oxygen values were very high, increasing along with salinity (maximum 176.1 at $95 \%$ ).

The most significant observations during the 36 test days concerned behavioral changes (Table 2). As such, at salinities of $20-30 \%$, all fish performed normal swimming movements and feeding was constant. After overcoming the $30 \%$ threshold, an accelerated swimming was noted, and fish stopped consuming the pellets offered. When salinity exceeded $50 \%$, the fish started to display an uncoordinated swimming behavior and no feeding was observed. At salinities between $70 \%$ and $90 \%$, partial immobility was observed, as fish rested close to the aquarium bottom and no feeding was documented. 
Table 2. Behavioral response of $C$. auratus to extreme salinity.

\begin{tabular}{lc}
\hline Extreme Salinity & Ethological response of fish \\
\hline $20-30 \% \circ$ & Normal swimming/feeding \\
$30-50 \%$ occelerated swimming/no feeding \\
$50-70 \%$ Uncoordinated swimming/ no feeding \\
$70-90 \%$ Partial immobility/no feeding \\
$90-95 \%$ Total immobility and death \\
\hline
\end{tabular}

During the last day of the test, when salinity reached the peak value of $95 \%$, all fish became totally immobile and finally died, due to the impossibility of osmotic regulation. These behavioral effects are all consistent with other findings regarding mullets' response to high temperatures and salinities, which state that the fish became stressed, showing dark coloration, loss of appetite and abnormal swimming behavior, and ultimmately death (Hotos \& Vlahos, 1998).

\section{Conclusions}

The results of our research on golden grey mullet C. auratus fries collected from Romanian Black Sea shallow waters indicate that they can tolerate a wide range of temperatures and salinities, which makes them an appropriate species for extensive and semi-intensive aquaculture, in open (flow-through) systems (ponds, lagoons, close to the coast), applicable in the northwestern part of the Black Sea, area subject to significant environmental variations, due to the influence of the Danube's freshwater input.

The salinity tolerance experiment revealed that increases in fish length were recorded in all salinity regimes, with the highest in the $15 \%$ and $0.3 \%$ aquaria (by $8.82 \%$ and $8.24 \%$, respectively). Overall, except for the $20 \%$ salinity, all fish grew more in length than in weight, regardless of the salinity regime. The highest increase in weight (by $12.04 \%$ ) was recorded in the $20 \%$ o salinity regime, while in the freshwater aquarium the weight increase was negative $(-2.05)$ (probably influenced by the small number of surviving fish for the final measurement). For the remaining salinities, weight gains were positive, slightly increasing in correlation with salinity (by $0.43 \%, 3.04 \%$ and $3.22 \%$, corresponding to $5 \%, 10 \%$ and $15 \%$ o salinities, respectively). The results obtained for the Condition Factor $(K)$ indicate an overall good state of the fries, with $K$ values ranging between 1.35 and 1.72, with the best condition being reported for fish kept at a $20 \%$ salinity. These findings indicate that the optimal salinity range for golden grey mullet fries is between $10 \%$ and $20 \%$ salinity. Moreover, $C$. auratus fries can tolerate even lower salinities (5\%), with no major disturbances of growth and overall behaviour, which makes them good candidates for brackish Black Sea water aquaculture.

The temperature tolerance test revealed that golden grey mullet fries can tolerate a wide range of temperature (from $8^{\circ} \mathrm{C}$ to $34^{\circ} \mathrm{C}$ ), with an optimal range for rearing between $10-25^{\circ} \mathrm{C}$, values at which fish swim and feed normally.

The extreme salinity tolerance test showed that at salinities of $20-30 \%$, all fish still swam and fed normally. After the $30 \%$ o threshold, swimming abnormalities were observed, along with refusal to feed, which culminated, at $90-95 \%$, with complete immobility and ultimately death of all fish caused by the impossibility of osmoregulation.

The aggregated conclusions of the three experiments are that golden grey mullet fries can tolerate temperatures from $8^{\circ} \mathrm{C}$ up to $36^{\circ} \mathrm{C}$, with an optimal range for rearing between $10-25^{\circ} \mathrm{C}$, with no behavioral alterations. Regarding salinity, our findings showed that $C$. auratus fries can indeed tolerate an extremely wide range, from $5 \%$ up to $70 \%$, yet the optimal salinity for rearing is between $10 \%$ and $30 \%$, even which makes them excellent candidates for the enhancement of aquaculture in the Romanian Black Sea area

\section{References}

Allen, G.R. (1991). Field Guide to the Freshwater Fishes of New Guinea. Publication, no. 9, Christensen Research Institute, Madang, Papua New Guinea: 268 pp.;

American Fisheries Society (2004). Guidelines for the Use of Fishes in Research. Retrieved from https://fisheries.org/docs/policy_useoffishes.pdf;

American Veterinary Medical Association (AVMA) (2013). Guidelines for the Euthanasia of Animals. ISBN 978-1882691-21-0, Version 2013.0.1, Retrieved from https://www.avma.org/resources-tools/avmapolicies/avma-guidelines-euthanasia-animals;

Barton, B.A. \& Iwama, G.K. (1991). Physiological Changes in Fish from Stress in Aquaculture with Emphasis on the Response and Effects of Corticosteroids. Annual Review of Fish Diseases 1, 3-26. https://doi.org/10.1016/09598030(91)90019-G;

Bozkurt, Y. \& Secer, S. (2001). Effects of Usage in Different Proportion to Manufactured Feed and Fish Meat on Growth Performance in Feeding of Fries of Mullet (Mugil sp.) in Turkish Waters. XI. National Fisheries Symposium, 4-6 September 2001, Hatay, Turkey;

Cardona, L. (2000). Effects of Salinity on the Habitat Selection and Growth Performance of Mediterranean Flathead Grey mullet, M. cephalus (Osteichthyes, Mugilidae). Estuarine, Coastal and Shelf Sciences 50 (5), 727-737. https://doi.org/10.1006/ecss.1999.0594;

Cardona, L. \& Castello-Orvay, F. (1997). Effetti della salinita sul tasso di accrescimento e sul consume di ossigeno di esemplari di un anno di muggine bosega (Chelon labrosus). Rivista Italiana di Acquacoltura 32 (1), 31-35; 
Crosetti, D. \& Cataudella, S. (1995). The Mullets (pp. 253-268), In: C.E. Nash, A.J. Novotny (Eds.). World Anim. Sci.Production of Aquatic Animals (fishes-C8). Elsevier Science, Amsterdam, Netherlands, 529 pp.;

EPA (2002). Methods for Measuring the Acute Toxicity of Effluents and Receiving Waters to Freshwater and Marine Organisms, Fifth Edition, Retrieved October 2002;

EPA (2016). Ecological Effects Test Guidelines, OCSPP 850.1075, 2016: Freshwater and Saltwater Fish Acute Toxicity Test, EPA, Retrieved October 2016;

Guino-o, R.S. (2012). Length-Weight and Length-Length Relationships and Fulton Condition Factor of Philippine Mullets (Family Mugilidae: Teleostei). Silliman Journal 53 (2), 176-189;

Hotos, G.N. \& Katselis, G.N. (2011). Age and Growth of the Golden Grey Mullet Liza aurata (Actinopterygii: Mugiliformes: Mugilidae), in the Messolonghi-Etoliko Lagoon and the Adjacent Gulf of Patraikos, Western Greece. Acta Ichthyologica et Piscatoria 41(3), 147-157. https://doi.org/10.3750/AIP2011.41.3.01;

Hotos, G.N., \& Vlahos, N. (1998). Salinity Tolerance of Mugil cephalus and Chelon labrosus (Pisces: Mugilidae) Fry in Experimental Conditions. Aquaculture 167, 329-338. https://doi.org/10.1016/S0044-8486(98)00314-7;

Katselis, G., Koukou, K., Dimitriou, E. \& Koutsikopoulos, C. (2007). Short-term Seaward Fish Migration in the Messolonghi - Etoliko Lagoons (Western Greek Coast) in Relation to Climatic Variables and the Lunar Cycle. Estuarine. Coastal and Shelf Science 73, 571-582. https://doi.org/10.1016/j.ecss.2007.02.010;

Lee, C.S. (1997). Marine Finfish Hatchery Technology in the USA - Status and Future. Academic Publishers, Belgium. Hyrobiologia 358, 45-54. https://doi.org/10.1023/A:1003163919114;

Lefeuvre, J.C., Laffaille, P. \& Feunteun, E. (1999). Do Fish Communities Function as Biotic Vectors of Organic Matter between Saltmarshes and Marine Coastal Waters? Aquatic Ecology 33, 293-299. https://doi.org/10.1023/A:1009956605842;

Losse, G.F., Nau, W. \& Winter M. (1991). Le developpement de la peche en eau douce dans le nord de la Tunisie-Project de cooperation technique Tuniso-Allemande, Projet "Utilisation de barrages pour la pisciculture". GTZ and CGP, Tunis. 1991, 418 pp.;

Mansour, C.R. (2013). Acclimation Trial of Liza aurata Fingerlings to Fresh Water and to a Low Water Salinity. Tishreen University Journal for Research and Scientific Studies - Biological Sciences Series 35 (4), 223-232;
Mylonas, C.C., Grigorakis, K., Rosenfeld, H., Koven, W., Guerrero, L. \& Robles R. (2019). Expert Topic: Grey Mullet. AquaFeed Magazine, 15 August 2019. Retrieved from https://aquafeed.co.uk/entrada/expert-topic-grey-mullet-20941;

Nicolaev, S., Zaharia, T. \& Oros A. (Eds.) (2019). Current State of the Marine and Coastal Environment. CD PRESS Publishing, Bucharest: 213 pp. (in Romanian);

Niță, V. \& Nenciu, M. (2017). Using Recirculating Technology in Pilot-System for Mariculture at the Romanian Black Sea Coast. Journal of Environmental Protection and Ecology 18 (1), 255-263;

Niță, V., Nenciu, M. \& Nicolae, C.G. (2018). Experimental Rearing of the Golden Grey Mullet Liza aurata (Risso, 1810) in a Recirculating System at the Black Sea Agriculture for Life, Life for Agriculture Conference Proceedings 1 (1), 149-154. https://doi.org/10.2478/alife-2018-0022;

Nordlie, F.G., Szelistowski, W.A. \& Nordlie, W.C. (1982). Ontogenesis of Osmotic Regulation in the Striped Mullet, Mugil cephalus. Journal of Fisheries Biology 20, 79-86. https://doi.org/10.1111/j.1095-8649.1982.tb03896.x;

Olukolajo, S.O. \& Omolara, L.A. (2013). Salinity Tolerance of Grey Mullet Mugil cephalus (Linnaeus) Fry in the Laboratory. Journal of Fisheries Sciences 7(4), 292-296. https://doi.org/10.3153/jfscom.2013031;

Pillia, T.G. (1975). Possibilities de l'aquaculture et developpement de la peche en eau douce et saumatre en Tunisiee. Ministere de l'Agriculture. Bulletin des Peches 2, 69-131;

Reis, I. \& Ateş, C. (2019). Length-Weight, Length-Length Relationships and Condition Factor of grey mullet species from Köyceğiz Lagoon in Turkey. Acta Aquatica Turcica, 15(4), 411-417. https://doi.org/10.22392/actaquatr.540983;

Suresh, K. (2011). An Overview of Randomization Techniques: An Unbiased Assessment of Outcome in Clinical Research. Journal of Human Reproduction Sciences 4(1), 8-11. https://doi:10.4103/0974-1208.82352;

Verdiell-Cubedo, D., Oliva-Paterna, F.J. \& Torralva, M. (2006). Length-Weight Relationships for 22 Fish Species of the Mar Menor Coastal Lagoon (Western Mediterranean Sea). Journal of Applied Ichthyology 22, 293-294. https://doi.org/10.1111/j.1439-0426.2006.00738.x;

Zaharia, T., Niță, V. \& Nenciu M. (2017). Background of Romanian Marine Aquaculture. CD PRESS Publishing, Bucharest, 273 pp. (in Romanian) 